\title{
Deliçay ile Tarsus (Berdan) Çayı Arasındaki Bölgede Yer Alan Kuvaterner Sedimanlarının Mineralojik ve Jeokimyasal Özellikleri
}

\author{
Mineralogical and Geochemical characteristics of Quaternary Sediments from the Area \\ Between Deliçay and Tarsus (Berdan) Rivers
}

\author{
Mehmet Ali KURT ${ }^{1}$, Musa ALPASLAN ${ }^{2}$, Abidin TEMEL ${ }^{3}$, Cüneyt GÜLER \\ ${ }^{1}$ Mersin Üniversitesi, Illeri Teknoloji Ĕgitim, Araştırma ve Uygulama Merkezi, Çiftlikköy Kampüsü, \\ Mersin(e-posta:mehmetalikurt@gmail.com) \\ ${ }^{2}$ Mersin Üniversitesi, Mühendislik Fakültesi, Jeoloji Mühendisliği Bölümü, Çiftlikköy Kampüsü, Mersin \\ ${ }^{3}$ Hacettepe Üniversitesi, Mühendislik Fakültesi, Jeoloji Mühendisliği Bölümü, 06532 Beytepe, Ankara
}

\section{$\ddot{O Z Z}$}

Bu çalışmada, Deliçay ile Tarsus Çayı (Mersin) arasındaki bölgede yer alan Kuvaterner çökellerinin mineralojik ve jeokimyasal özelliklerinin belirlenmesi ve kökensel farklılıklarının ortaya konulması amaçlanmıştır. Çalışma alanı topraklarının mineralojisini belirlemek için 40 ayrı noktadan ve üç farklı derinlikten toplam 120 adet örnek alınmıştır. Ayrıca, yüzey $(0-15 \mathrm{~cm})$ topraklarının dokusal ve jeokimyasal özelliklerini belirlemek amacıyla toplam 208 adet örnek alınmıştır. Toprak örneklerinin mineralojik bileşimleri XRD yöntemiyle, dokusal özellikleri Bouyoucos hidrometre yöntemiyle ve jeokimyasal özellikleri ise ICP-MS yöntemiyle belirlenmiştir. Bu çalışmadan elde edilen tüm veriler bir Coğrafi Bilgi Sistemi (CBS) veritabanına aktarılarak çeşitli dağılım haritaları oluşturulmuştur. Ayrıca, $\mathrm{Ni}, \mathrm{Cr}$, Co ve Fe elementleri arasındaki ilişkileri ortaya koymak amacıyla ikili değişim diyagramları oluşturulmuştur. Dağılım haritalarından ve değişim diyagramlarından elde edilen sonuçlara göre; çalışma alanındaki Kuvaterner çökellerinin mineralojik ve jeokimyasal olarak iki farklı kökenden kaynaklandığı belirlenmiştir. Köken farklılığına göre delta çökelleri, jeokimyasal ve mineralojik bileşim olarak batı ve doğu bölümü toprakları olmak üzere iki farklı kısıma ayrılmaktadır. Bu ayrımı, Kuvaterner çökellerinin oluşumunda önemli rol oynayan Deliçay ve Tarsus Çayı'nın farklı kaynaklardan getirdikleri jeolojik malzeme sağlamıştır. Çalışma alanındaki Kuvaterner çökelleri; kuzey-güney yönünde çökellerdeki tane boyu bakımından, bat1-doğu yönünde ise jeokimyasal ve mineralojik olarak farklılıklar göstermektedir. Anahtar Kelimeler: Deliçay, Kuvaterner çökelleri, Tarsus çayı, toprak jeokimyası, toprak mineralojisi. 


\section{ABSTRACT}

In this study, it was aimed to determine mineralogical and geochemical properties and differences in sources of the deltaic sediments from the area between Deliçay and Tarsus rivers (Mersin). A total of 120 samples were taken from 40 different locations and from three different depth intervals to determine mineralogical characteristics of the soils from the study area. Furthermore, a total of 208 samples were taken for determination of textural and geochemical properties of the topsoils $(0-15 \mathrm{~cm})$. Mineralogical composition of soil samples were determined with XRD method, followed by determination of textural and geochemical properties with Bouyoucos hydrometer and ICP-MS methods, respectively. All the data obtained in this study were compiled into a Geographic Information System (GIS) database for preparation of various thematic map layers. Furthermore, scatter plots were also used to explore the relationship between the elements such as $\mathrm{Ni}, \mathrm{Cr}, \mathrm{Co}$, and $\mathrm{Fe}$. The results obtained from thematic map layers and scatter plots suggest that deltaic sediments in the study area originated from two different sources that differ in mineralogical and geochemical characters. According to mineralogical and geochemical differences in these sources, Quaternary sediments in the study area can be divided into two separate parts, such as western and eastern soils. This differentiation is caused by the geological materials brought from different sources by the Deliçay and Tarsus rivers, which also played important roles in the formation of Quaternary sediments. Quaternary sediments in the study area display differences in textural properties in the north-south direction, whereas showing differences only in geochemical and mineralogical properties in the west-east direction.

Key Words: Deliçay river, Quaternary deposits, soil geochemistry, soil mineralogy, Tarsus river.

\section{GíRíş}

Nehir ve 1rmak gibi büyük akarsular delta özellikli ovaların oluşumunu sağlayan en büyük etmendir. Ceyhan ve Seyhan nehirleri ile Tarsus Çayı da (Berdan Nehri) Çukurova'nın şekillenmesinde rol alan büyük boyutlu akarsulardır (Gürbüz, 1997). $\mathrm{Bu}$ nehirler kuzey ve batıdan Toros Dağları, doğudan Amanos Dağları ve Misis Yükselimi, güneyde ise Akdeniz ile çevrili Miyosen yaşl1, 6-10 km kalınlığındaki Adana Baseni istifini keserek Akdeniz'e dökülmektedir (Gürbüz, 1997). Deliçay ve Müftü Deresi gibi bölgede sayıları onlarla ifade edilebilen akarsular ise Çukurova'nın şekillenmesinde rol alan küçük boyutlu ikincil akarsulardır. Çalışma alanının doğu bölümünde yer alan ve Bolkar Dağları'nın eteklerinden kaynaklanan Tarsus Çayı, Berdan Barajı'nın kuzeyinde iki ana kolun birleşmesinden oluşmaktadır. $\mathrm{Bu}$ kollardan birincisi Gülek ve Kadıncık derelerinin birleşmesiyle oluşan doğu koludur. Kale Dere ve Cehennem Dere'nin birleşmesi sonucu oluşan Pamukdere de batıdaki koldur. Tarsus Çayı, Çamlıyayla ilçesinin doğu ve batı bölümlerindeki kaynak ve derelerden doğar (Şekil 1). Deliçay ise; Arslanköy, Kızılbăg, Ayvagediği ve Gözne bölgelerindeki küçük kaynak ve derelerin birleşmesi sonucu oluşmuştur. Deliçay’ın kaynağı Bolkar Dağları'nın Arslanköy bölümleri, Tarsus Çayı'nın kaynağı ise Çamlıyayla bölümleridir (Şekil 1).

Akarsular, yüksek dağlık kesimlerden getirdikleri malzemeleri enerjilerinin bittiği düzlük alanlara bırakarak delta çökellerini oluşturmaktadır. Delta çökelleri genel olarak kaynak bölgenin jeolojik özelliklerini yansitırlar (Prakongkep vd., 2008). Bundan dolayı, delta 
çökelleri veya dere sedimanlarına ait jeokimyasal veriler maden aramalarında uzun yıllardan beri sıklıkla kullanılmaktadır. Bu jeokimyasal veriler son yıllarda kirlilik kaynaklarının ve çökellerin ayrışma-taşınma süreçlerinin belirlenmesinde de kullanılmaktadir (Ranasinghe vd., 2008). Toprakların elementel bileşimleri türedikleri anakayanın bileşimini ve ayrışma süreçlerini yansitmaktadır (Prakongkep vd., 2008). Jeokimyasal olarak deltalar; anakayadan türeyen bileşenler ( $\mathrm{Al}, \mathrm{Ca}, \mathrm{Co}, \mathrm{Cr}, \mathrm{Fe}, \mathrm{K}, \mathrm{Mg}, \mathrm{Na}$ ve $\mathrm{Ni})$ ve insan aktiviteleri sonucu oluşan kirletici bileşenlerden (As, $\mathrm{Cd}, \mathrm{Cu}, \mathrm{Hg}, \mathrm{Pb}$ ve $\mathrm{Zn}$ ) oluşmaktadır (Pasternack ve Brown, 2006). Delta çökellerinin veya dere sedimanlarının jeokimyasal ve kökensel özelliklerine dair literatürde yapılmış çok sayıda çalışma vardır (Kosters vd., 2000; Amorosi ve Milli, 2001; Tareq vd., 2003; Borrego vd., 2005; El-Kammar vd., 2007; Singh, 2009; Ranasinghe vd., 2009).

Gürbüz(2003), doğuAkdenizbölgesindeki akarsuların ovaya getirdikleri sedimanların çok az litolojik değişiklik gösterdiğini ve bunların benzer litolojilerden oluşan geniş bir kaynak alandan türediğini belirtmektedir. Çukurova bölgesinde akarsular ve bunların getirdikleri delta çökelleri ile ilgili sınırlı sayıda çalışma vardır (Erinç, 1953; Evans, 1971; Göney, 1976; Bal, 1983; Erol, 1983; Gürbüz, 1997; 1999; 2003; Çetin vd., 1999). Bu çalışmalar daha çok bu nehirlerin oluşumları ve evrimleri, delta kumullarının yaşlarının ve kıyı değişimlerinin belirlenmesi ile ilgilidir. Kurt vd. (2009a), Deliçay ile Tarsus Çayı arasında görülen çökellerin tane boyu dağılımı ve mineralojik bileşimi ile ilgili bir çalışma yapmıştır. $\mathrm{Bu}$ çalışmada, kıyıya yakın bölümlerde hakim tane boyunun kum olduğu, buna karşın kıyıdan uzak kuzey bölümlerde ise kil ve silt boyutunda malzemelerin ağırlık kazandığı belirtilmektedir. Bölgede genel jeolojik amaçlı (Çavuşgil, 1985; Şenol, 1989; Şenol vd., 1993; 1998) ve toprak kirliliğine yönelik çok sayıda çalışma vardır (Topak, 1997; Aysan, 1999; Köleli ve Halisdemir, 2005; Kurt vd., 2008; 2009b; 2009c; Güler, 2009). Buna karşın bölgedeki delta çökellerinin mineralojik bileşim ve jeokimyasal özellikleri ile ilgili kapsamlı bir çalışma bulunmamaktadır.

Bu çalışmanın amacı; Deliçay ile Tarsus Çayı arasında kalan bölgede yüzeyleyen delta çökellerinin mineralojik ve jeokimyasal olarak kökenini belirlemek ve varsa farklılıklarını ortaya koymaktır. Çalışma alanı, 1/25.000 ölçekli Mersin O33-a3, O33-b1, O33-b2, O33-b3 ve O33-b4 paftaları içerisinde yer almaktadır. Bu alan, batıda Deliçay, doğuda Tarsus Çayı (Berdan Nehri), kuzeyde Mersin-Tarsus karayolu ve güneyde Akdeniz tarafından sınırlandırılan yaklaşı 234 $\mathrm{km}^{2}$ 'lik bir alandır (Şekil 1). 


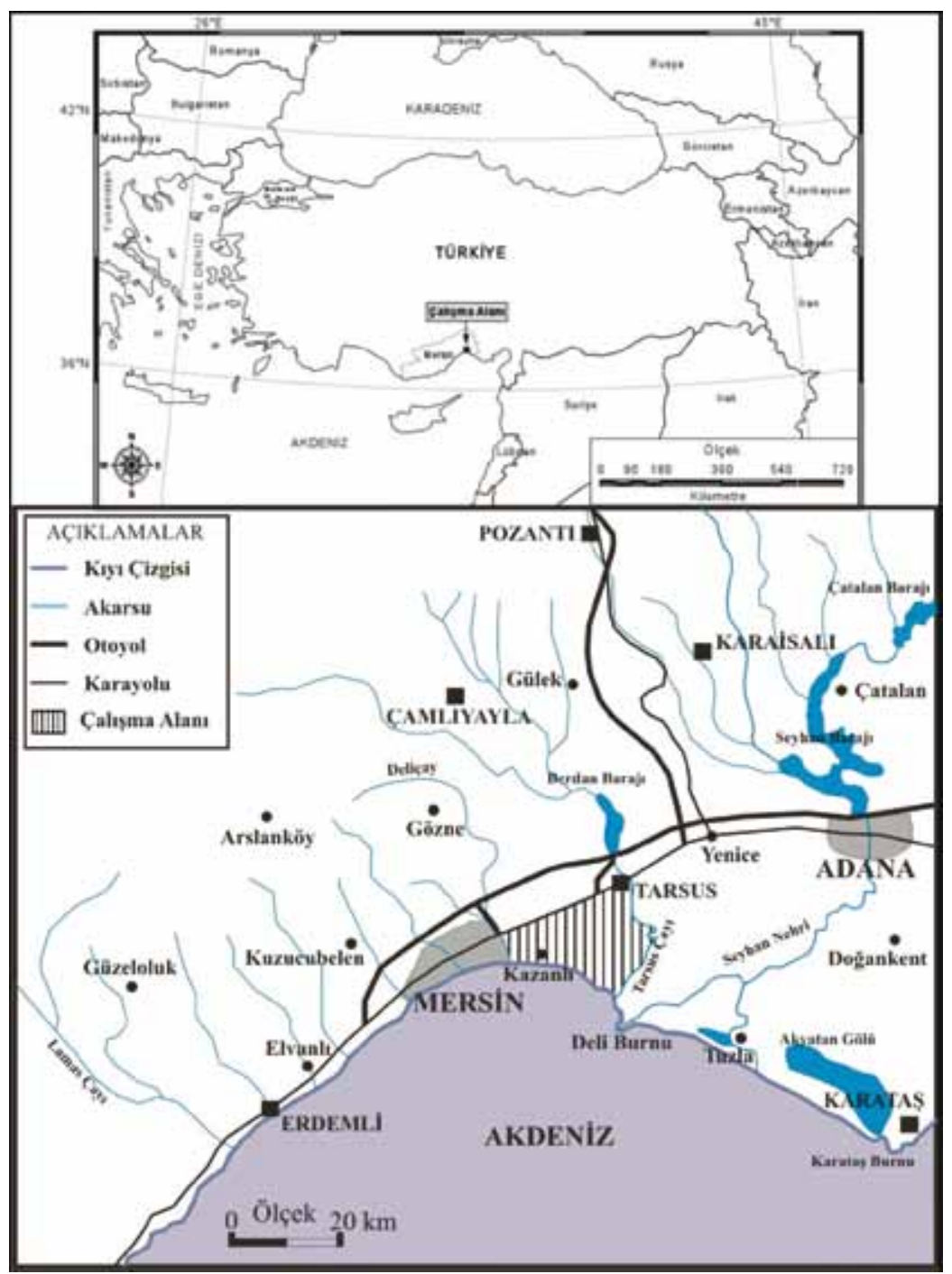

Şekil 1. Çalışma alanının yer bulduru haritası.

Figure 1. Location map of the study area.

\section{MATERYAL VE METOT}

Deliçay ile Tarsus Çayı arasında kalan bölgedeki toprakların mineralojisini belirmek için Şubat 2007'de 40 ayrı noktanın 3 farklı derinliğinden (A seviyesi $=0-20 \mathrm{~cm}, \mathrm{~B}$ seviyesi $=60-80 \mathrm{~cm}$ ve $\mathrm{C}$ seviyesi $=120-140 \mathrm{~cm}$ ) toplam 120 adet toprak örneği alınmıştır. Ayrıca, toprakların dokusal özelliklerini ve jeokimyasal bileşimini belirlemek amaciyla, Ağustos 2007'de toplam 208 adet yüzey $(0-15 \mathrm{~cm})$ toprak örneği alınmıştır.
Toprak örneklerinin mineralojik bileşimlerinin tespit edilmesi için gerekli olan tüm kayaç ve kil mineralojisi çözümlemeleri XRD cihazıyla, dokusal özellikleri ise Bouyoucos hidrometre yöntemiyle (Bouyoucos, 1951) belirlenmiştir. Toprak örneklerinin kireç içeriklerini belirlemek için Bernard kalsimetresi kullanılmıştır (Gedikoğlu, 1990). Bir ardışıklı süzdürme yöntemiyle (5 aşamalı) (Väisänen ve Kiljunen, 2005) sıv1 faza alınan toprak örneklerinin tüm jeokimyasal analizleri Agilent 7500ce marka 
ICP-MS cihazı (Tokyo, Japonya) ile yapılmıştır. Elde edilen tüm veriler bir Coğrafi Bilgi Sistemi veritabanına aktarılarak çeşitli dağılım haritaları oluşturulmuştur. Dağılım haritaları ve değişim diyagramları yardımıyla, çalışma alanındaki delta çökellerinin kökenlerine yönelik çeşitli yorumlamalar yapılmıştır.

\section{GENEL JEOLOJI்}

Mersin ili ve çevresi Orta ve Doğu Toroslar'ın batı bölümünde yer almakta olup bölgede çok sayıda litolojik birim yer almaktadır (Şekil 2). Bu birimler; Permo-Karbonifer yaşlı temel birimler, bunların üzerinde yer alan Jura-Kretase yaşlı ofiyolit ve ofiyolitik melanj, post-tektonik özellikli ve genellikle ofiyolitik birimleri örten Tersiyer birimleri ve Kuvaterner döneminde oluşan karasal çökel birimleridir.

\section{Genellikle meta-kireçtaşları ve şistlerden} oluşan Paleozoyik yaşlı Karahamzauşağ Formasyonu bölgedeki temel kaya birimidir. Mersin Ofiyoliti ve Mersin Ofiyolitik Melanj1, Karahamzauşağı Formasyonu üzerinde yer alan tektonik dokanaklı birimlerdir. Genellikle karbonat ve kırıntılı çökellerden oluşan Tersiyer birimleri ofiyolitik kayaçlar üzerine uyumsuz olarak gelmektedir. Tersiyer kayaçlarını açısal uyumsuzlukla örten Kuvaterner yaşlı kıyı kumulları ve delta çökelleri bölgedeki en genç birimlerdir.

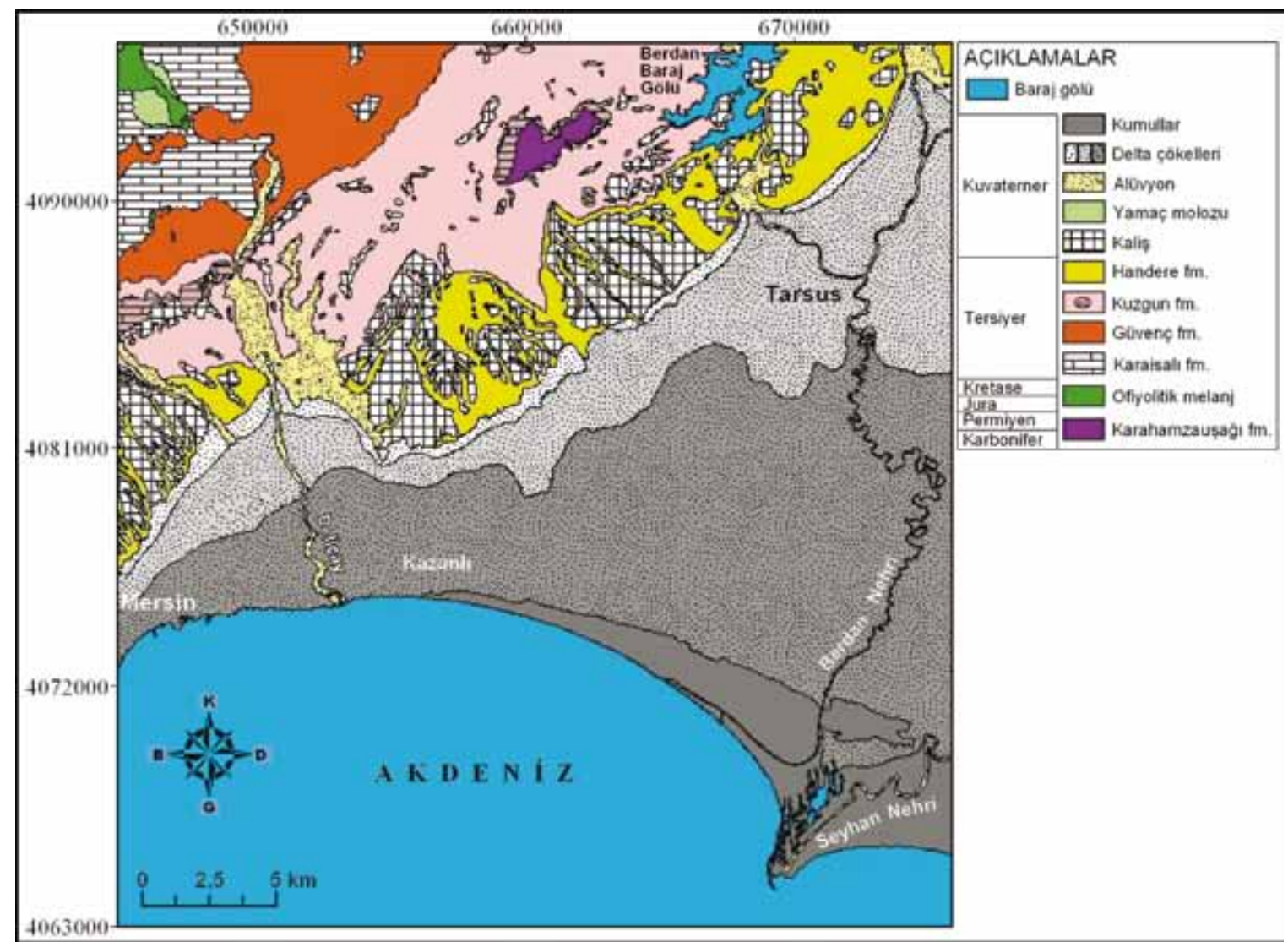

Şekil 2. Çalışma alanı ve yakın civarının jeolojik haritası (Şenol vd., 1998 ve Güler vd., 2009'dan değiştirilerek).

Figure 2. Geology map of the study area and surrounding region (modified from Şenol et al., 1998 and Güler et al., 2009). 
Çalışma alanının da içerisinde yer aldığı Çukurova'nın Kuvaterner jeolojisi ile ilgili çok sayıda çalışma vardır (Bal, 1983; Çavuşgil, 1985; Şenol, 1989; Şenol vd., 1993; 1998; Gürbüz, 1997; Gürbüz, 1999; Öner vd., 2002; Gürbüz, 2003; Öner vd., 2005a; Öner vd., 2005b; Darbaş vd., 2008; Kurt, 2010; Lécuyer, 2012; Güler vd., 2013). Çalışma alanında, Kuvaterner döneminde karasal ve geçiş ortamını temsil eden birimler çökelmiş olup bu birimler fasiyes özelliklerine göre stratigrafik olarak Kalabriyen-Siciliyen birimleri ve Tirreniyen-Güncel birimleri olarak ikiye ayırmıştır (Şenol vd., 1993). Alttaki birimleri açısal uyumsuz olarak örten ve üstündeki birimler tarafindan uyumsuz olarak örtülen Kalabriyen-Siciliyen birimleri; alüvyon yelpazesi çökelleri/yüksek seki konglomeraları, fan delta çökelleri ve kıyı çökelleri ile pedalojik oluşuklar, Akdeniz kırmızı toprağı ve sert kalişlerden oluşmaktadır (Şenol vd., 1998). Kalabriyen-Siciliyen birimleri üzerine uyumsuz olarak gelen Tirreniyen-Güncel birimleri ise yamaç molozları, akarsu seki konglomeraları, delta çökelleri, kıyı çökelleri, kumul ve pedolojik oluşuklardan meydana gelmiştir (Şenol vd., 1993). Çalışma alanı sınırları içerisinde bu birimlerden delta çökelleri ve kıyı kumulları yer almaktadır. Siciliyen sonlarında Adana bölgesinde meydana gelen çöküntü alanlarının daha sonra oluşan akarsu ve kolları tarafından getirilen materyallerle dolması sonucu delta çökelleri birikmiş ve bu çökeller stratigrafik olarak alttan üste ve karadan denize doğru Dç1, Dç2 ve Dç3 olarak üçe ayrılmıştır (Şenol vd., 1993). Çalışma alanı içerisinde, delta çökellerinden Dç3 ve Dç2 yer almakta olup, Dç3 çok daha geniş bir yayılıma sahiptir. Kıyı kumulları çalışma alanında Deliçay-Tarsus Çayı arasındaki kıyı şeridi boyunca doğudan batıya doğru incelen bir yayılım göstermektedir (Şekil 2).

\section{Toprakların Tane Boyu Dağılımı}

Deliçay ile Tarsus Çayı arasındaki Kuvaterner çökellerinin kil, silt ve kum içeriklerinin dağılımı Şekil 3'te verilmektedir. Toprak örneklerinin kum içeriklerinin dağılımına bakıldığında (Şekil 3), kum içeriği yüksek örneklerin Akdeniz sahiline paralel 2-3 km'lik bir bölümde yer aldığı ve Kazanlı kasabası civarında son bulduğu görülür. $\mathrm{Bu}$ alan çalışma alanının jeolojik haritasında (Şekil 2) kıyı kumulları olarak adlandırılan alana karşılık gelmektedir. Buna karşın bölgedeki Kuvaterner çökellerinin kil ve silt içeriklerinin (Şekil 3) ise güneyden kuzeye doğru gidildikçe kademeli olarak arttığı ve çalışma alanının kuzey sınırı olan Mersin-Tarsus karayoluna yakın bölümlerde yer alan toprakların kil içeriklerinin oldukça yüksek olduğu görülmektedir.

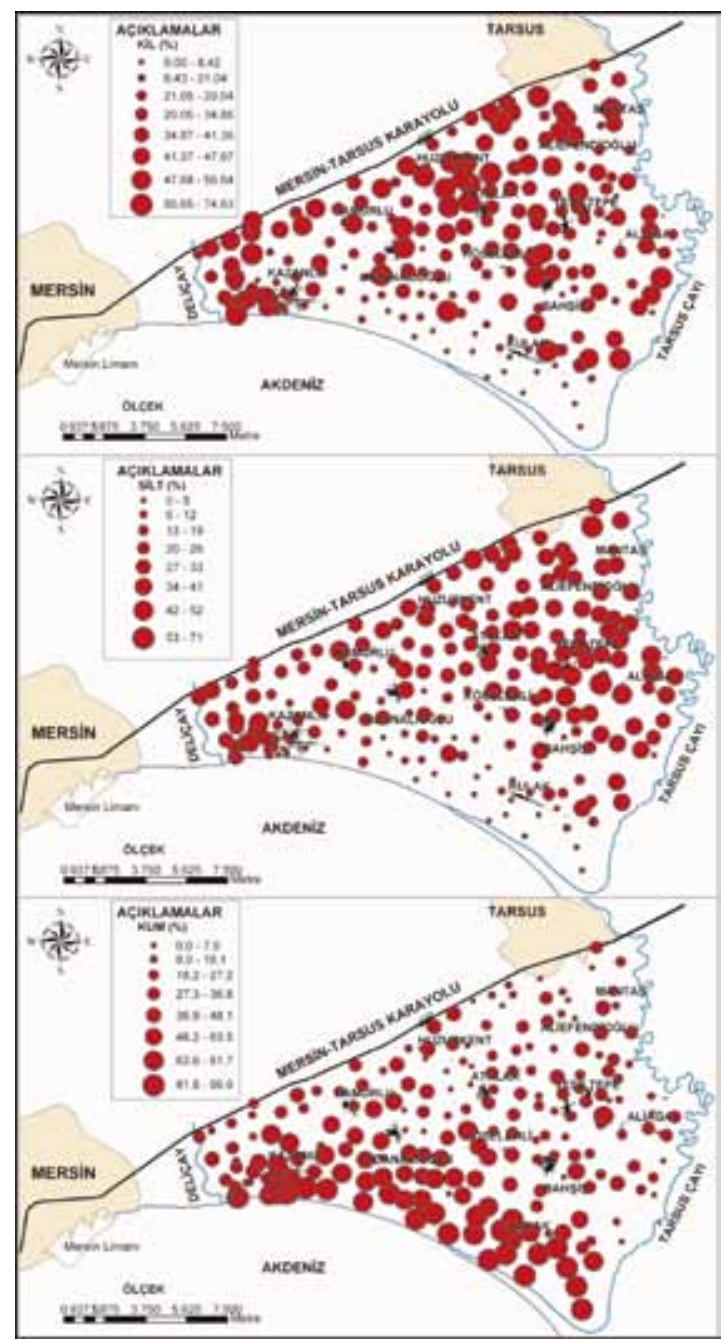

Şekil 3. Deliçay ve Tarsus Çayı arasında yer alan Kuvaterner çökellerinin kil, silt ve kum içeriklerinin alansal dağılımı.

Figure 3. Spatial distribution of the clay, silt and sand content of Quaternary sediments from the area between Deliçay and Tarsus rivers. 


\section{Çalışma Alanı Topraklarının Mineralojik Özellikleri}

Çalışma alanındaki toprak profillerinin mineralojisini belirlemek amaciyla, 40 ayrı noktanın üç farklı derinliğinden alınan toplam 120 adet toprak örneğinin XRD tüm kayaç çözümlemeleri ve 16 adet örneğin XRD kil bileșeni çözümlemeleri yapılmıştır. Tüm kayaç çözümlemelerine göre çalışma alanı toprakları ağırlıklı olarak kil, kalsit, kuvars, feldispat, mika, dolomit ve amfibol minerallerinden oluşmaktadır. Kil mineralojisi çözümlemelerine göre Deliçay ile Tarsus Çayı arasındaki Kuvaterner çökelleri, simektit, klorit, illit, kaolinit ve serpantin türü killerden oluşmaktadır. Simektit grubu killer bölge topraklarında genel olarak en yaygın görülen kil türüdür.

Şekil 4'te Kuvaterner çökellerinin üç farklı seviyesindeki $(0-20 \mathrm{~cm}, 60-80 \mathrm{~cm}$ ve $120-140$ $\mathrm{cm})$ kuvars yüzdelerinin dağılımı görülmektedir. Toprak profillerinin $\mathrm{A}, \mathrm{B}$ ve $\mathrm{C}$ seviyeleri genel olarak benzer bir mineralojik dağılım göstermektedir (Şekil 4). Çalışma alanının batı bölümlerinde A seviyesindeki toprak örneklerinin üçü hariç tümü yüksek oranda kuvars (\%16-28) içerirken; doğu bölümlerindeki topraklardan dördü hariç (\%13-18) tümü düşük oranda (\%615) kuvars içermektedir. Şekil 4'e bakıldığında genel olarak, çalışma alanının batı bölümlerindeki toprakların doğu bölümdeki topraklara göre daha yüksek oranda kuvars içerdikleri görülür.

Şekil 5'te çalışma alanı toprak profillerinde mika yüzdelerinin dağılımı görülmektedir. Bölge topraklarının $\mathrm{A}, \mathrm{B}$ ve $\mathrm{C}$ seviyelerindeki mika minerallerinin dağılımı genel olarak benzerdir. Batı bölümde dört örnek hariç tüm örnekler düşük oranda (\%0-9) mika içerirken; doğu bölüm topraklarının üçü hariç tümü daha yüksek miktarda mika içermektedir. Çalışma alanının doğu bölümündeki topraklar batı bölümündeki topraklara göre daha yüksek miktarda mika içermektedir (Şekil 5). Çalışma alanının doğu bölümündeki toprakların daha yüksek miktarda mika içermesi, doğu bölümü besleyen Tarsus Çayı'nın batı bölüme göre metamorfik kayaçlardan daha fazla beslendiğini göstermektedir.

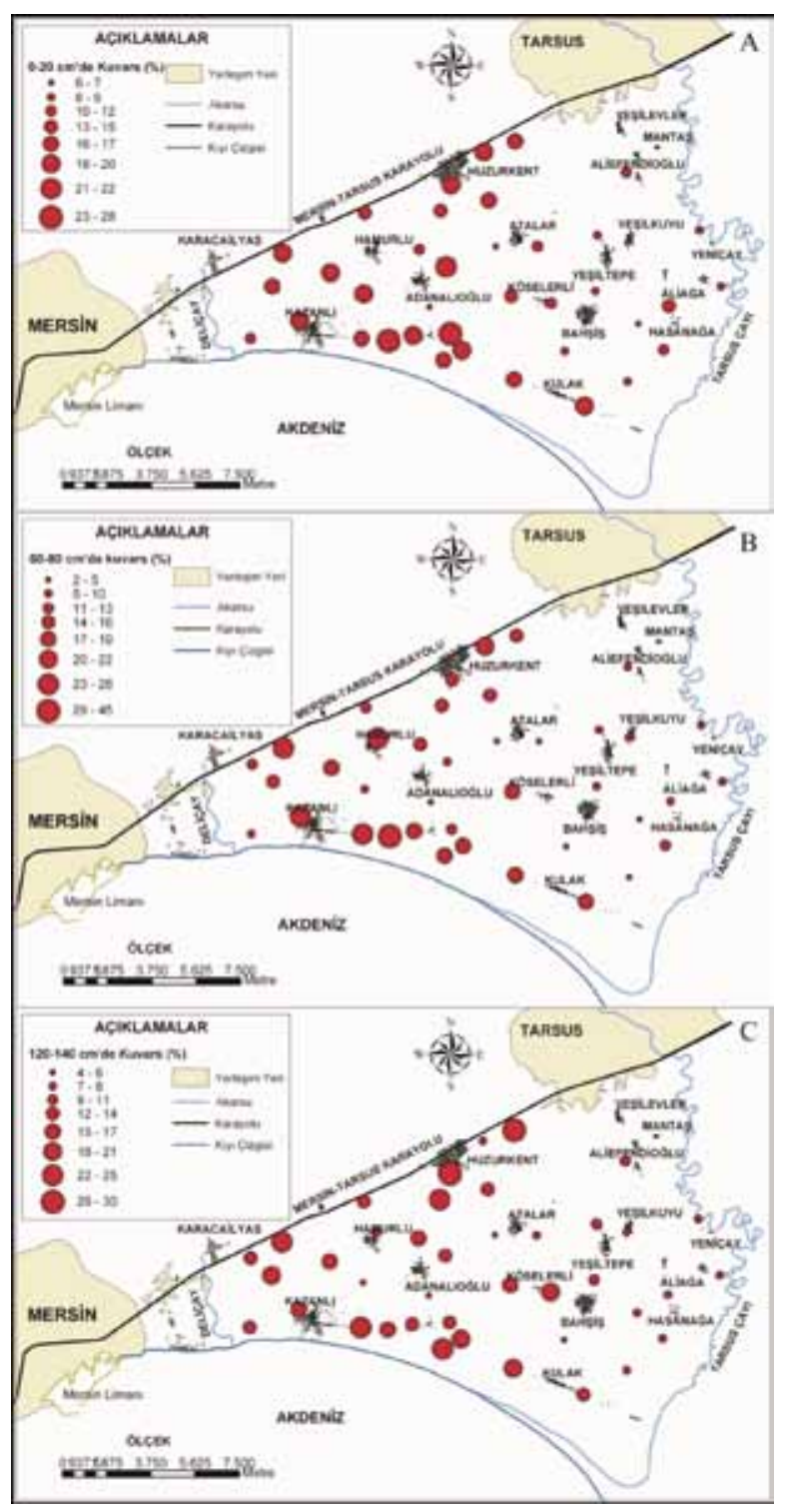

Şekil 4. Delta çökellerinin üç farklı seviyesinde belirlenen kuvars yüzdelerinin alansal dağılımı.

Figure 4. Spatial distribution of the quartz percentages determined in three different levels of the deltaic sediments. 


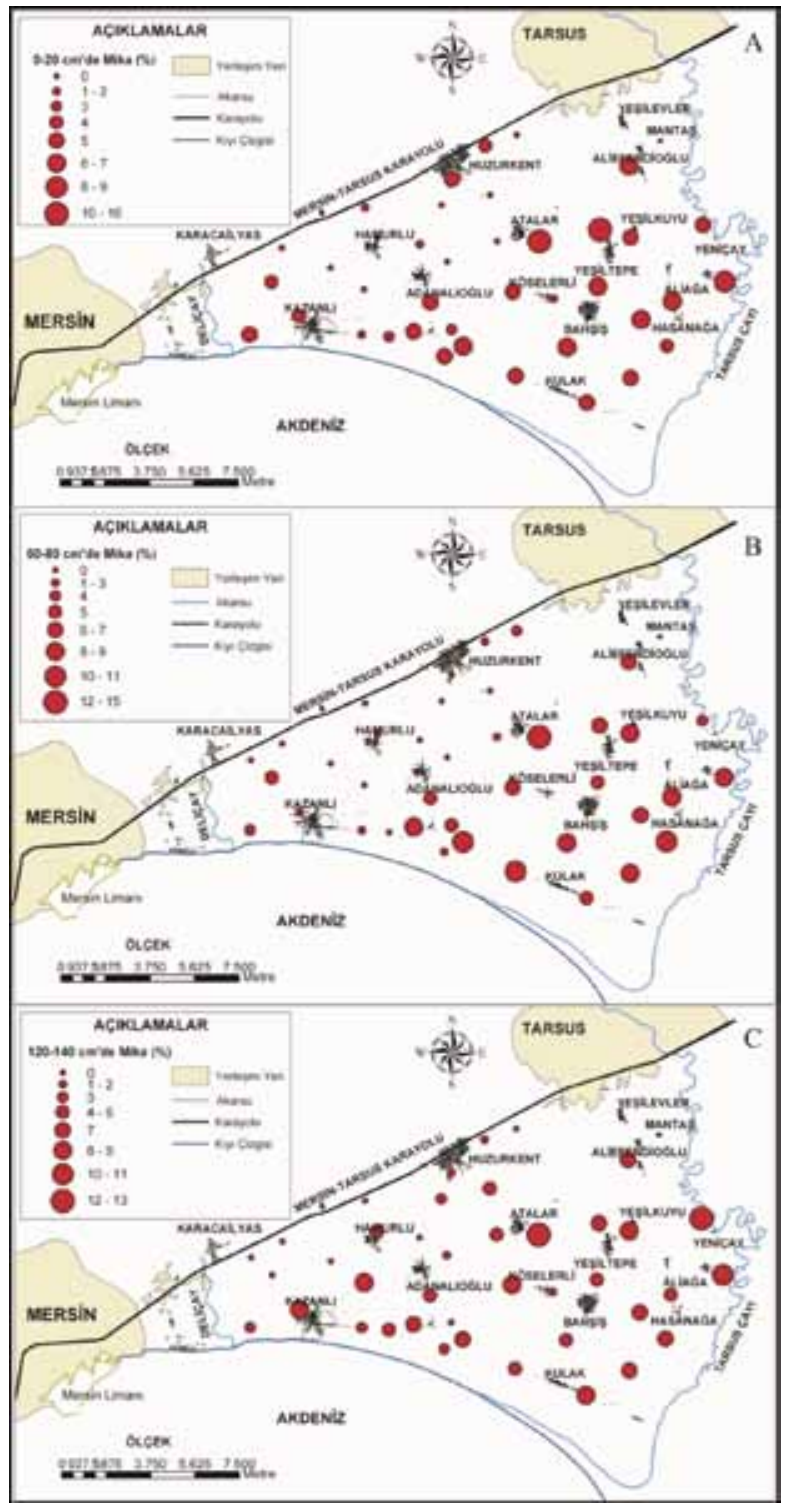

Şekil 5. Delta çökellerinin üç farklı seviyesinde belirlenen mika yüzdelerinin alansal dağ 1 lımı.

Figure 5. Spatial distribution of the mica percentages determined in three different levels of the deltaic sediments.

Çalışma alanı topraklarının en büyük, en küçük ve ortalama $\mathrm{CaCO}_{3}$ içerikleri sırasıyla $\% 49,9 ; \% 1,3$ ve $\% 29,2$ 'dir. Çalışma alanındaki toprak örneklerinin karbonat içeriklerinin dağılımı Şekil 6'da görülmektedir. Bu şekilde, kabaca doğu bölüm topraklarının, batı bölüm topraklarına göre daha yüksek karbonat içerdiği görülmektedir. Özellikle Tarsus Çayı'na paralel olan bölüm topraklarının $\mathrm{CaCO}_{3}$ içerikleri daha yüksektir
(Şekil 6). Doğu bölüm çökellerinin karbonatça daha zengin olması Tarsus Çayı'nın kireçtaşından daha fazla beslendiğini göstermektedir. Bat1 bölümde yer alan Kazanlı kasabası civarındaki toprakların $\mathrm{CaCO}_{3}$ değerleri oldukça düşüktür. Ancak, batı bölümde de Hamurlu ile Adanalığlu kasabaları civarında yüksek $\mathrm{CaCO}_{3}$ değerlerine sahip alanlar mevcuttur (Şekil 6). 


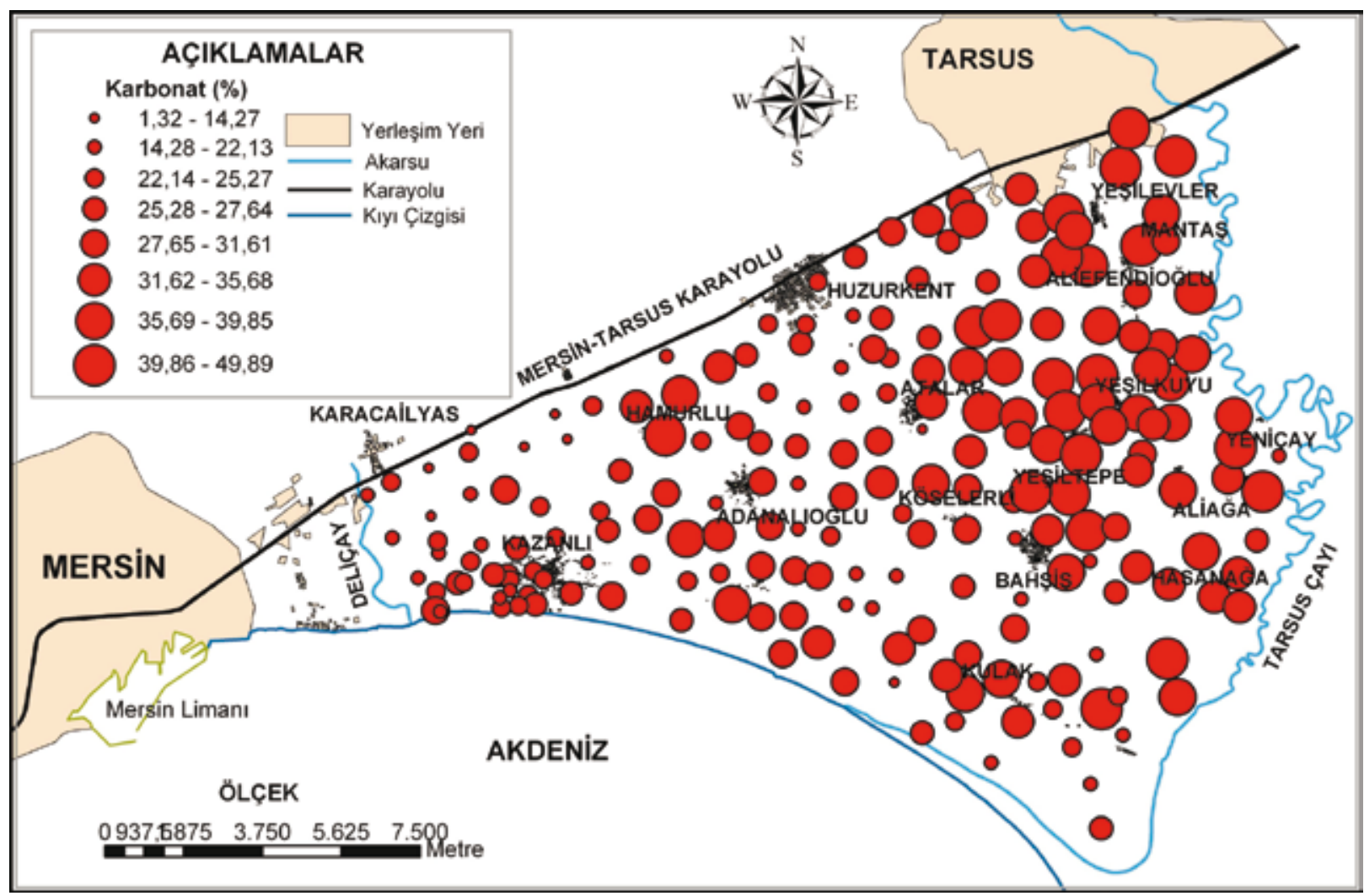

Şekil 6. Delta çökellerinde belirlenen $\mathrm{CaCO}_{3}$ yüzdelerinin alansal dağılımı.

Figure 6. Spatial distribution of the $\mathrm{CaCO}_{3}$ percentages determined in deltaic sediments.

\section{TOPRAK JEOKIMYASI}

Delta çökelleri türedikleri kaynak bölgenin jeokimyasal özelliklerini taşırlar (Chandrajith vd., 2000; Prakongkep vd., 2008). Çalışma alanındaki delta çökellerinin birikimini Mersin ilinin kuzeyinden beslenen Deliçay ile Tarsus Çayı (Berdan Nehri) sağlamıştır. Bu akarsuların kaynak bölgelerinde ofiyolitik kayaçlar mevcuttur. Nikel, krom, kobalt ve demir elementleri de ultramafik ve mafik kayaçlarda zenginleşme gösteren elementlerdir. $\mathrm{Bu}$ elementler aynı zamanda kaynak bölgedeki ofiyolitik kayaçlarda da zenginleşme göstermektedirler (Yaman, 1991; Güler vd., 2010). Bu çalışmada özellikle Cr, Co, $\mathrm{Fe}$ ve Ni elementleri jeokimyasal olarak benzer davranışlar gösterdikleri için ve kaynak bölgede bu elementlerce zengin kayaçlar olduğu için seçilmiştir. Deliçay ile Tarsus Çayı'nın kaynak bölgeleri farklıdır. Farklı kaynak bölgelere sahip olan bu akarsuların ovaya getirmiş oldukları delta çökellerinin jeokimyasal özelliklerinde bir takım farklılıkların olup olmadığı bu bölümde irdelenmiştir.

Çalışma alanında görülen toprakların kimyasal bileşimleri, bir ardışıklı süzdürme yöntemiyle (beş aşamalı) elde edilen çözeltiden ICP-MS yöntemiyle belirlenmiştir. $\mathrm{Bu}$ ardışıklı süzdürme yönteminin aşamaları şöyle sıralanabilir: (1) suya geçen/kolaylıkla değişebilir faz, (2) karbonatlara bağlanan faz, (3) Fe ve Mn oksit 
fazları, (4) organik madde fazları ve (5) silikat fazlarıdır (Vaisanen ve Kiljunen, 2005). İlk dört aşama antropojenik olarak toprakta biriken faz, son aşama olan silikat fazı ise litolojik olarak toprakta bulunan fazdir. Cr, Co, Fe ve Ni elementleri 208 örneğin hemen hemen tümünde beşinci aşama olan silikat fazında en fazla zenginleşmişlerdir. $\mathrm{Bu}$ elementlerin özellikle silikat fazındaki konsantrasyonunun kaynağı, bölgede yaygın olarak görülen ofiyolitik kayaçlardır.

$\mathrm{Bu}$ elementlerin birbirine göre ikili değişim diyagramlarında belirgin bir ayrımlaşma olup, örnekler iki farklı bölgede kümelenme göstermektedirler. $\mathrm{Bu}$ çalışmada, Deliçay ile Tarsus Çayı arasındaki Kuvaterner çökellerinin grafiklerde göstermiş oldukları ayrımlaşmadan dolayı örnekler batı bölüm toprakları ve doğu bölüm toprakları olarak iki kısıma ayrılmışlardır. Deliçay ile Tarsus Çayı arasındaki bölge topraklarının ve dünya topraklarının(Bowen, 1979) $\mathrm{Cr}, \mathrm{Co}$, Ni ve Fe element konsantrasyonlarının en düşük, en yüksek ve ortalama değerleri Çizelge 1'de verilmektedir. Bu çizelgeye göre; hem doğu bölüm topraklarının, hem de batı bölüm topraklarının Ni konsantrasyonları ve batı bölüm topraklarının Co konsantrasyonları dünya ortalamasının çok üzerindedir. Buna karşın, hem doğu bölüm topraklarının, hem de batı bölüm topraklarının $\mathrm{Cr}$ ve $\mathrm{Fe}$ konsantrasyonları dünya ortalamasının altındadır (Çizelge 1). Çalışma alanı topraklarının $\mathrm{Cr}, \mathrm{Co}$, Ni ve Fe element içerikleri arasında doğru orantılı bir ilişki vardır. Çizelge 2'de batı ve doğu bölüm topraklarının $\mathrm{Cr}, \mathrm{Co}, \mathrm{Ni}$ ve Fe element konsantrasyonlarının korelasyonu ayrı ayrı verilmiştir. Batı bölüm topraklarında en yüksek korelasyon Fe ve Ni arasındadır $(r=0,91)$. Buna karşın batı bölüm topraklarında en düşük korelasyon ise $\mathrm{Fe}$ ve $\mathrm{Cr}$ elementleri arasindadır $(r=0,18)$. Doğu bölüm topraklarındaki Ni, Co ve $\mathrm{Cr}$ elementleri arasında yüksek korelasyon $(r$ $=0,61-0,85)$ varken, $\mathrm{Ni}$, Co ve Cr elementlerinin Fe elementi ile korelasyonları ise düşüktür ( $r=$ $0,16-0,37)$.

Çizelge 1. Çalışma alanı toprakları ile dünya toprakları ortalaması, kabuk değerleri ve Karaduvar (Mersin) topraklarının ortalama $\mathrm{Cr}, \mathrm{Co}, \mathrm{Ni}$ ve $\mathrm{Fe}$ konsantrasyonları (ppm).

Table 1. Mean values of $\mathrm{Cr}$, Co, Ni and Fe concentrations (ppm) of study area soil and world soils, crust, Karaduvar (Mersin) soils.

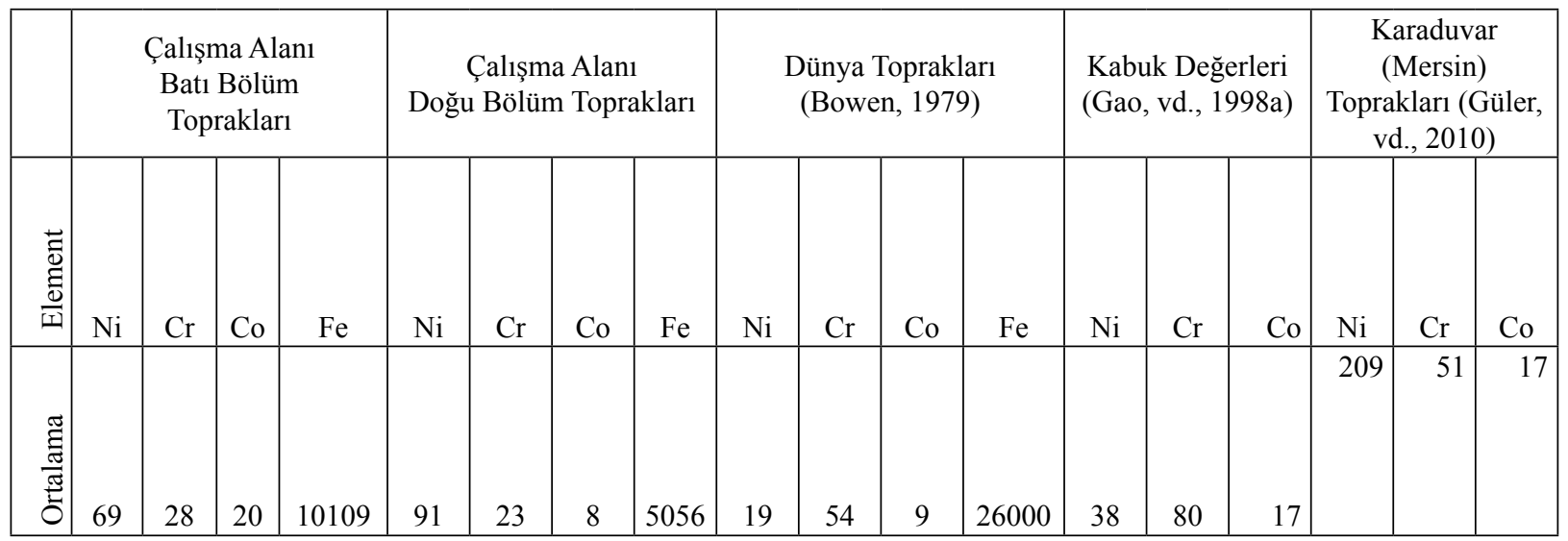


Şekil 7'de bölge topraklarının demir elementi ile nikel, krom ve kobalt elementleri arasındaki ilişki görülmektedir. Şekil 7a'daki Fe-Ni grafiğinde doğu bölüm toprakları ile batı bölüm topraklarının çok net bir şekilde ayrıldı̆̆ görülmektedir. Bu grafikte doğu bölüm toprakları, bat1 bölüm topraklarına göre genel olarak $\mathrm{Ni}$ bakımından daha zengin iken, batı bölüm toprakları da $\mathrm{Fe}$ bakımından daha zengindir. Şekil 7b'de çalışma alanı topraklarının Fe-Cr element içeriklerinin birbirine göre ikili değişimi yer almaktadır. Bu grafikte, doğu ve batı bölüm topraklarının ayrımı çok belirgin olmamakla birlikte, az da olsa bir ayrım söz konusudur. Şekil $7 \mathrm{c}$ 'de Fe-Co grafiğinde ise doğu bölüm toprakları ile batı bölüm topraklarının ayrımı belirgin olarak görülmektedir. $\mathrm{Bu}$ grafikte ayrıca batı bölüm topraklarının doğu bölüm topraklarına göre hem Co, hem de Fe bakımından daha zengin oldukları görülmektedir.

Çizelge 2. Çalışma alanı batı ve doğu bölüm topraklarında; $\mathrm{Ni}, \mathrm{Cr}$, Co ve $\mathrm{Fe}$ elementleri arasındaki korelasyon katsayıları $(r)$.

Table 2. Correlation coefficients ( $r$ ) between $\mathrm{Ni}$, $\mathrm{Cr}, \mathrm{Co}$ and $\mathrm{Fe}$ elements in the soils from western and eastern parts of the study area.

\begin{tabular}{|c|c|c|c|c|c|c|}
\hline \multicolumn{4}{|c|}{ Batı Bölüm Toprakları } & \multicolumn{3}{|c|}{$\begin{array}{l}\text { Doğu Bölüm } \\
\text { Toprakları }\end{array}$} \\
\hline Element & $\mathrm{Ni}$ & $\mathrm{Cr}$ & $\mathrm{Co}$ & $\mathrm{Ni}$ & $\mathrm{Cr}$ & Co \\
\hline $\mathrm{Cr}$ & 0,18 & & & 0,73 & & \\
\hline Co & 0,81 & 0,53 & & 0,85 & 0,61 & \\
\hline $\mathrm{Fe}$ & 0,91 & 0,18 & 0,79 & 0,18 & 0,16 & 0,37 \\
\hline
\end{tabular}

Şekil 8'de bölge topraklarının nikelkobalt, krom-nikel ve kobalt-krom element konsantrasyonlarının değişimleri görülmektedir. $\mathrm{Bu}$ grafikte doğu ve batı bölüm topraklarının ayrımlaşması oldukça belirgindir. Doğu bölüm toprakları genellikle yüksek nikel, düşük kobalt içerirken; batı bölüm topraklarının çoğu yüksek kobalt ve düşük nikel içermektedirler (Şekil 8a). Krom-nikel grafiğinde ise (Şekil 8b), hem doğu bölüm topraklarının hem de batı bölüm topraklarının krom içerikleri benzer aralıklarda değişirken; doğu bölüm topraklarının nikel değişim aralığı, batı bölüm topraklarının nikel değişim aralığından daha büyüktür. Şekil 8c'deki kobalt-krom grafiğinde, doğu ve batı bölüm topraklarının krom içeriği yaklaşık aynı aralıkta değişirken; batı bölüm topraklarının kobalt içeriklerinin değişim aralığı, doğu bölümün kobalt içeriklerinin değişim aralığından daha büyüktür. Şekil 8'deki üç grafik genel olarak incelendiğinde; doğu bölüm topraklarının batı bölüm topraklarına göre Ni bakımından daha zengin, buna karşın Co bakımından daha fakir olduğu görülür. Doğu ve batı bölüm toprakları genel olarak yaklaşık benzer oranlarda $\mathrm{Cr}$ elementi içermelerine rağmen, grafiklerdeki eğimleri birbirinden farklıdır. $\mathrm{Cr}$, $\mathrm{Ni}$, Co ve Fe elementlerinin birbirine göre değişim diyagramları, Deliçay ile Tarsus Çayı arasındaki bölgede yer alan delta çökellerinin iki farklı kökenden kaynaklandığını göstermektedir. 


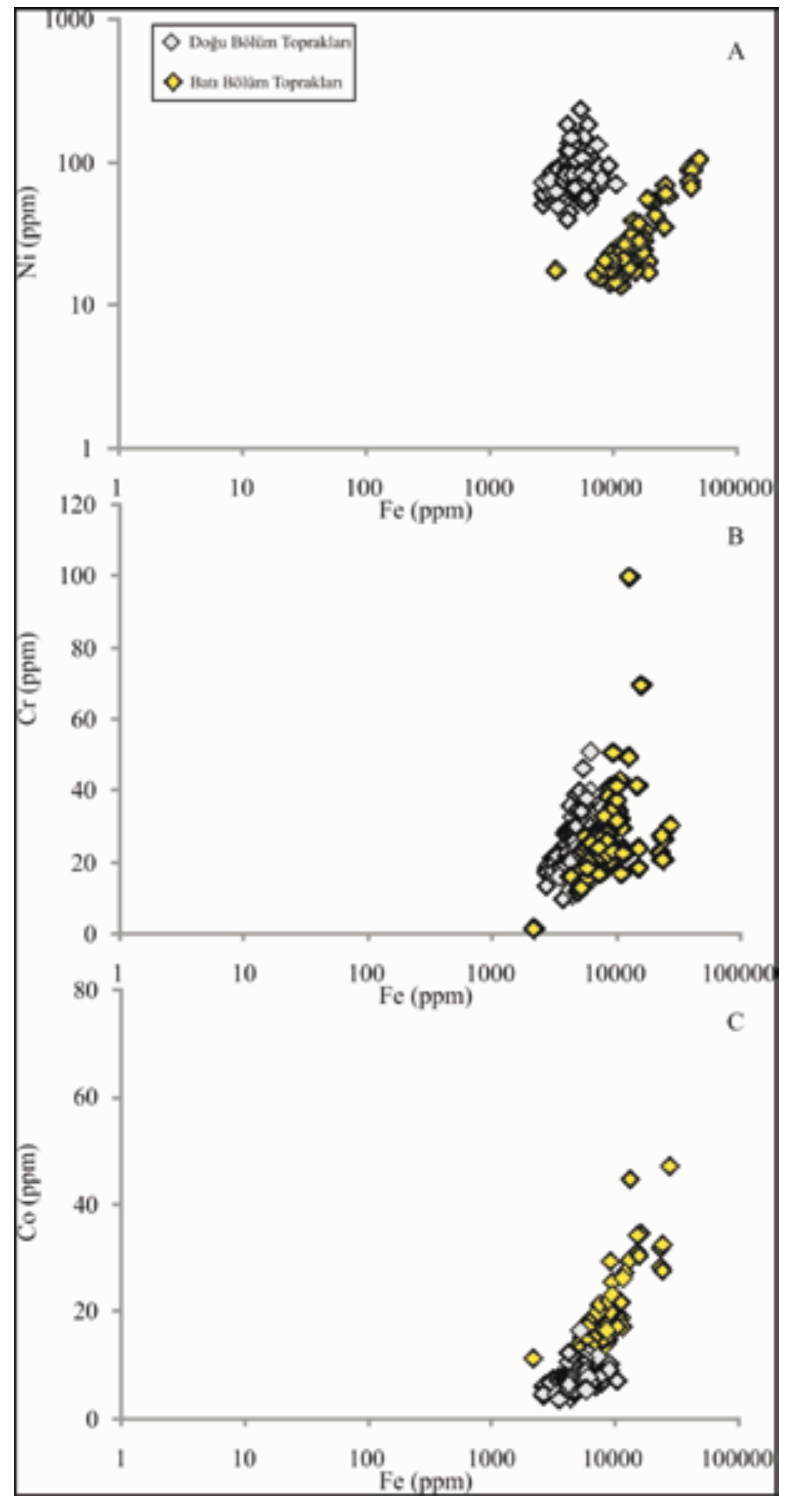

Şekil 7. Çalışma alanı topraklarında belirlenen Ni$\mathrm{Fe}, \mathrm{Cr}-\mathrm{Fe}$ ve Co-Fe elementlarine ait ikili değişim grafikleri.

Figure 7. Scatter diagrams for the elements $\mathrm{Ni}-\mathrm{Fe}$, $\mathrm{Cr}$-Fe and Co-Fe which were determined in the study area soils.

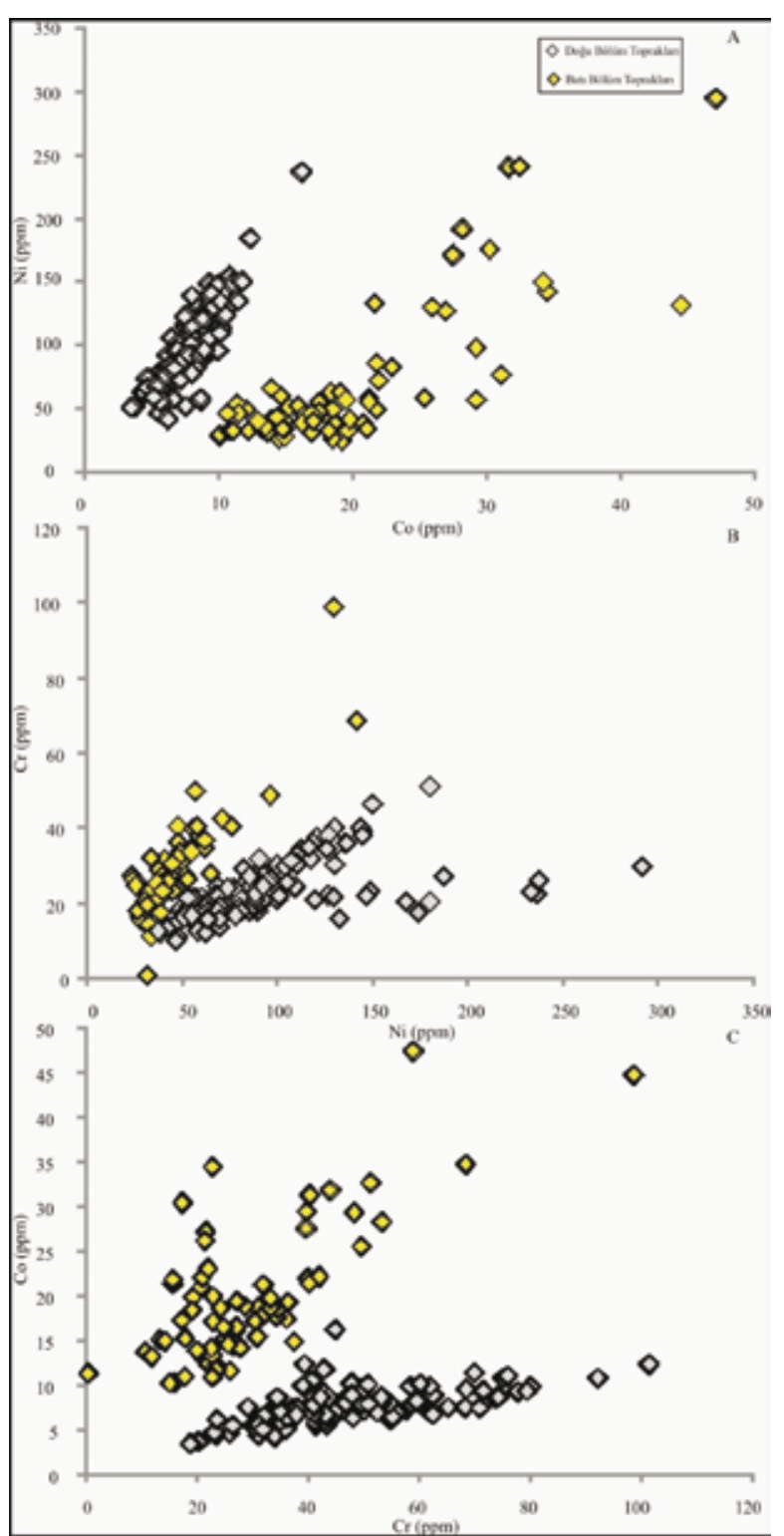

Şekil 8. Çalışma alanı topraklarında belirlenen Ni$\mathrm{Co}, \mathrm{Cr}-\mathrm{Ni}$ ve $\mathrm{Co}-\mathrm{Cr}$ elementlerine ait ikili değişim grafikleri.

Figure 8. Scatter diagrams for the elements $\mathrm{Ni}-\mathrm{Co}$, $\mathrm{Cr}$-Ni and $\mathrm{Co}-\mathrm{Cr}$ which were determined in the study area soils. 


\section{Doğu ve Batı Bölüm Toprakları}

Bu çalışmada; özellikle jeokimyasal olarak benzer davranış gösteren elementlerin ( $\mathrm{Cr}, \mathrm{Co}, \mathrm{Fe}$ ve Ni) birbirine göre ikili değişim grafiklerinden (Şekil 7 ve 8) elde edilen sonuçlara göre, bölge topraklarının iki farklı kökene ait oldukları belirlenmiştir. Ayrıca, bölge topraklarının bazı mineralojik bileşenlerinde de önemli farklılıklar gözlenmektedir (Şekil 4-6). Şekil 9'da, çalışma alanından alınan 208 toprak örneğinin dağılımı görülmektedir. $\mathrm{Bu}$ şekilde, yukarıda belirtilen jeokimyasal ve mineralojik verilere dayanarak çizilmiş olan doğu ve batı bölüm topraklarını ayıran ayrım çizgisi gösterilmiştir. Bu çizginin sağında kalan topraklar doğu bölüm toprakları, solunda kalan topraklar ise batı bölüm toprakları olarak adlandırılmıştır.

\section{TARTIŞMA ve SONUÇLAR}

Çalışma alanının doğu ve batı sınırlarını oluşturan Deliçay ve Tarsus Çayı, Bolkar Dağları'nın farklı bölümlerinden kaynaklanmaktadır. Deliçay, Bolkar Dağları'nın Arslanköy bölgesinden, Tarsus Çayı ise Çamlıyayla kesiminden doğar. $\mathrm{Bu}$ nedenden dolayı adı geçen akarsuların getirdikleri delta çökelleri mineralojik ve jeokimyasal olarak farklılıklar göstermektedirler. Çalışma alanında görülen Kuvaterner çökellerinin jeokimyasal ve mineralojik özelliklerinin şekillenmesinde, çalışma alanının doğu ve batı sınırını oluşturan Deliçay ve Tarsus Çayı etken olmuştur.

$\mathrm{Bu}$ çalışmada, bölge toprakları, jeokimyasal ve mineralojik bileşimlerindeki farklılıklarından dolayı doğu ve batı bölüm toprakları olarak iki bölüme ayrılmıştır. Çalışma

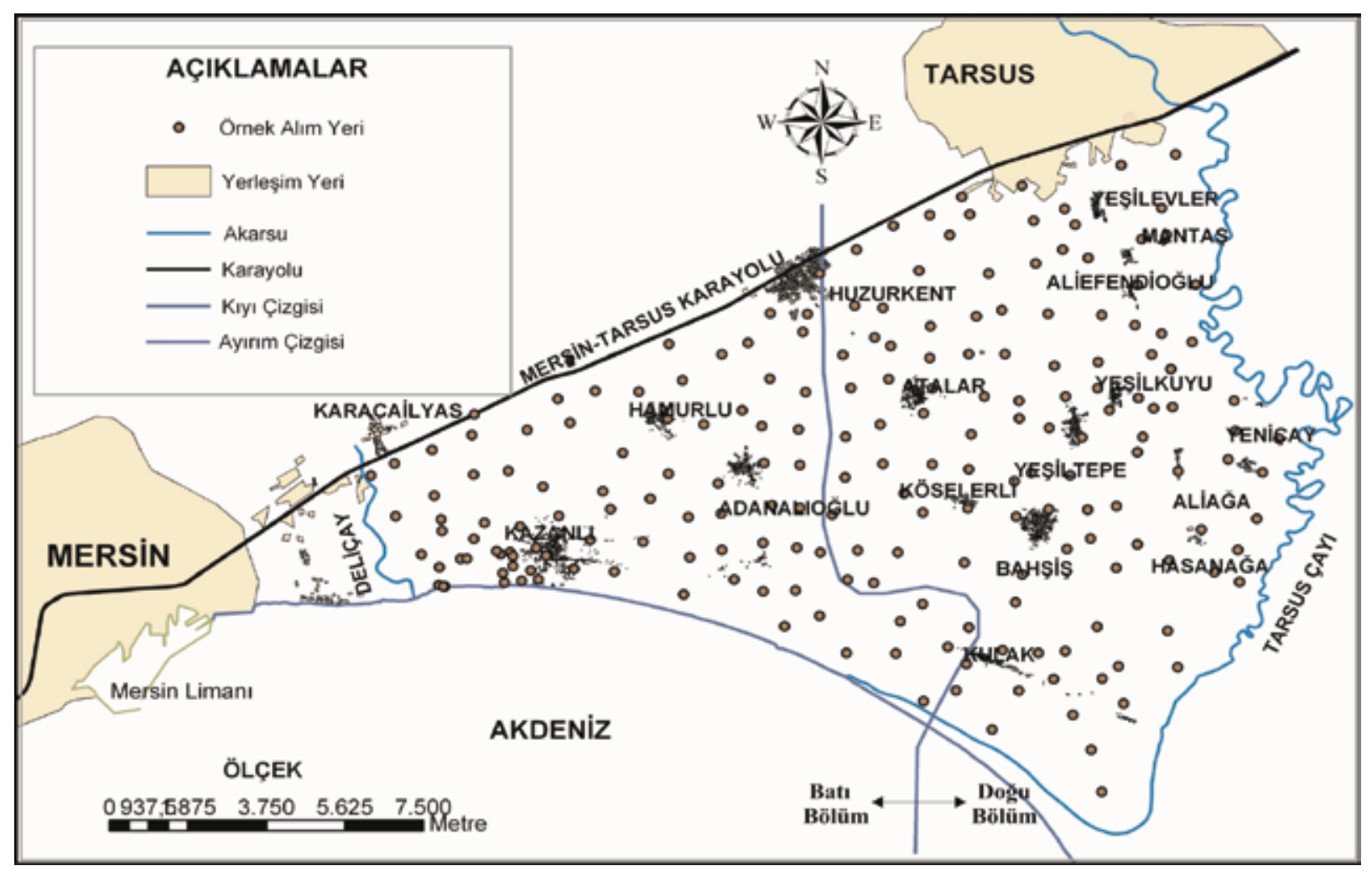

Şekil 9. Toprak örnekleme noktaları ve batı/doğu topraklarını ayıran sanal çizgi.

Figure 9. Soil sampling locations and the imaginery line separating west/east soils 
alanı topraklarının doğu ve batı bölüm olarak ikiye ayrılmasını, delta çökellerinin oluşumunda rol oynayan Deliçay ve Tarsus Çayı'nın farklı kaynaklardan getirdikleri jeolojik malzeme sağlamıştır. Doğu ve batı bölüm topraklarının kuvars, mika ve kalsit içerikleri birbirinden farklıdır. Çalışma alanı toprakları jeokimyasal olarak ise $\mathrm{Co}, \mathrm{Cr}$, $\mathrm{Ni}$ ve $\mathrm{Fe}$ element içerikleri bakımından farklılıklar göstermektedir. Özellikle jeokimyasal farklılaşmayı sağlayan $\mathrm{Co}, \mathrm{Cr}, \mathrm{Ni}$ ve Fe elementleri, bölgedeki ofiyolit ve ofiyolitik karmaşadan kaynaklanmaktadır. Jeokimyasal farklılaşmayı sağlayan etmen ya da etmenler, ofiyolitik dizilimin farklı seviyeleri ve/veya kaynak bölgelerdeki farklı ayrışma ve aşınma karakteristiklerinden kaynaklanmış olabilir. Deliçay ile Tarsus Çayı arasında kalan bölgedeki delta çökelleri, kuzey-güney yönde çökellerdeki tane boyu bakımından; doğu-batı yönünde ise jeokimyasal ve mineralojik olarak farklılıklar göstermektedir.

\section{KATKI BELİRTME}

$\mathrm{Bu}$ çalışma, Mersin Üniversitesi Bilimsel Araştırma Projeleri Birimi (BAP-FBE-JM (JM) 2007-2DR nolu proje) ve Devlet Planlama Teşkilatı (2006 K 120770 nolu proje) tarafindan maddi olarak desteklenmiş olup yazarlar desteklerinden dolayı bu kurumlara teşekkür ederler.

\section{EXTENDED SUMMARY}

Rivers, especially the large ones, are prominent factors that enable the formation of huge delta plains. Ceyhan, Seyhan and Tarsus (Berdan) rivers are the most important perennial rivers that take a significant part in the shaping of the Chukurova deltaic plain. These large rivers flow into the Mediterranean Sea after transversing the Miocene aged Adana Basin (with a thickness of 6-10 km), which is surrounded by Taurus Mountains in the north and west, Amanos Mountains and Misis Uplift in the east, and the Mediterranean Sea in the south. A heavy load of detritic material brought down by these rivers from the high mountainous areas is deposited as deltaic sediments in the flat areas where the water velocity is slower. In general, deltaic sediments reflect the geological properties of their source areas such as bedrock composition and dominant weathering processes. Therefore, geochemical data related to the delta or stream sediments have long been used in the mineral exploration studies. In recent years, this geochemical data is also utilized for identifying sources of pollution and determining weathering and transport processes of the sediments. Multielement sediment geochemical data can ve divided into two components; elements derived from the bedrock weathering ( $\mathrm{Al}, \mathrm{Ca}, \mathrm{Co}, \mathrm{Cr}, \mathrm{Fe}$, $\mathrm{K}, \mathrm{Mg}, \mathrm{Na}$, Ni, etc.) and pollutants resulting from anthropogenic activities (As, $\mathrm{Cd}, \mathrm{Cu}, \mathrm{Hg}, \mathrm{Pb}, \mathrm{Zn}$, etc.).

The study area is situated in fertile fluviodeltaic plains of two rivers, Deliçay and Tarsus (Mersin, SE Turkey) and stretches from MersinTarsus motorway in the north to the Mediterranean Sea in the south, covering an area about $200 \mathrm{~km}^{2}$. In this area, agricultural, industrial, and domestic activities are known to be very intense. In this study, it was aimed to determine mineralogical and geochemical properties and differences in sources of the Quaternary sediments from the area between Deliçay and Tarsus rivers. A total of 120 samples were taken from 40 different locations and from three different depth intervals to determine mineralogical characteristics of the soils from the study area. Furthermore, a total of 208 samples were taken for determination of textural and geochemical properties of the topsoils $(0-15 \mathrm{~cm})$. Mineralogical composition 
of soil samples were determined with XRD method, followed by determination of textural and geochemical properties with Bouyoucos hydrometer and ICP-MS methods, respectively. All the data obtained in this study were compiled into a Geographic Information System (GIS) database for preparation of various thematic map layers. Furthermore, scatter plots were also used to explore the relationship between the elements such as $\mathrm{Ni}, \mathrm{Cr}, \mathrm{Co}$, and $\mathrm{Fe}$. The results obtained from thematic map layers and scatter plots suggest that Quaternary sediments in the study area originated from two different sources that differ in mineralogical and geochemical characters. According to mineralogical and geochemical differences in these sources, deltaic sediments in the study area can be divided into two separate parts, such as western and eastern soils. This differentiation is caused by the geological materials brought from different sources by the Deliçay and Tarsus rivers, which played important roles in the formation of deltaic sediments.

Mineral (quartz, mica and calcite) and elemental (Co, $\mathrm{Cr}, \mathrm{Ni}$ and $\mathrm{Fe}$ ) contents of the soils from the western and eastern parts also significantly differ from each other. Especially, elements providing the geochemical differentiation (Co, $\mathrm{Cr}, \mathrm{Ni}$ and $\mathrm{Fe}$ ), are sourced from ophiolite and ophiolitic mélange units found in the area. In summary, Quaternary sediments in the study area display differences in textural properties in the north-south direction, whereas showing differences only in geochemical and mineralogical properties in the west-east direction.

\section{DEĞİNILLEN BELGELER}

Amorosi, A. and Milli, S., 2001. Late Quaternary depositional architecture of Po and Tevere river deltas (Italy) and worldwide comparison with coeval deltaic successions. Sedimantary Geology, 144 (3-4), 357-375.
Aysan, H., 1999. Adana-Tarsus güneyinde kalan bölgenin serbest akifer ve topraklarındaki ağır metal kirliliğinin saptanması. Çukurova Üniversitesi Fen Bilimleri Enstitüsü, Adana, Doktora Tezi, 133 s (yayımlanmamış).

Bal, Y., 1983. Doğu Akdeniz kıyı çizgisi değişimleri. Çukurova Üniversitesi Fen Bilimleri Enstitüsü, Adana, Yüksek Lisans Tezi, $67 \mathrm{~s}$ (yayımlanmamış).

Borrego, J., López-González, N., Carro, B. and Lozano-Soria, O., 2005. Geochemistry of rare-earth elements in Holocene sediments of an acidic estuary: Environmental markers (Tinto River Estuary, South-Western Spain). Journal of Geochemical Exploration, 86 (3), 119-129.

Bouyoucos, G.J., 1951. A recalibration of the hydrometer method for making mechanical analysis of soils. Agronomy Journal, 43 (9), 434-438.

Bowen, H.J.M., 1979. The Environmental Chemistry of the Elements, Academic Press, New York.

Çetin, H., Bal, Y. and Demirkol, C., 1999. Engineeering and environmental effects of coastline changes in Turkey, northeastern Mediterranean. Environmental \& Engineering Geoscience, 5 (3), 315-330.

Chandrajith, R., Dissanayake, C.B., Tobschall, H.J., 2000. The stream sediment geochemistry of the Walawe Ganga Basin of Sri Lanka - implications for Gondwana mineralisation. Gondwana Research, 3 (2), 189-204.

Çavuşgil, V.L., 1985. Adana-Kurttepe akarsu sekilerinde yeralan Akdeniz kırmızı topraklarının oluşumları ve birbirleri ile olan ilişkisi üzerinde bir araştırma. Çukurova Üniversitesi Fen Bilimleri Enstitüsü, Adana, Doktora Tezi, $198 \mathrm{~s}$ (yayımlanmamış).

Darbaş, G., Nazik, A., Temel, A. and Gürbüz, K., 2008. A paleoenvironmental test for Messinian Salinity Crisis using Miocene-Pliocene clays, Adana Basin, southern Turkey. Applied Clay Sciences. 40, 108-118.

DSI, 1978. Mersin, Berdan ve Efrenk Ovaları Hidrojeolojik Etüd Raporu. Ankara.

El-Kammar, A.M., Arafa, I.H. and El-Sheltami, O.R., 2007. Mineral composition and environmental geochemistry of the beach sediments along the eastern side of the Gulf of Suez, Egypt. Journal of African Earth Sciences, 49 (3), 103-114.

Erinç, S., 1953. Çukurova'nın alüvyal morfolojisi hakkında. İstanbul Üniversitesi Coğrafya Enstitüsü Dergisi, 3 (4), 149-159.

Erol, O., 1983. Historical changes on the coastline of Turkey. Proceedings "Coastal Problems in the Mediteranean Sea" Eric, C., F. Bird and Paolo Fabbri (Editors), Bologna, 95-107.

Evans, G., 1971. Recent sedimentation of Turkey and adjacent Mediterranean and Black seas: a review. In A.S. Campbell 
(Editor), Geology and History of Turkey. Petr. Expl. Soc., Tripoli, Libya, 385-406.

Gao, S., Luo T. C., Zhang, B. R., Zhang, H. F., Han, Y. W., Hu, Y. K. and Zhao Z. D., 1998a. Chemical composition of the continental crust as revealed by studies in east China. Geochim. Cosmochim. Acta, 62, 1959-1975.

Gedikoğlu, I., 1990. Toprak verimliliğinin tayininde kullanılan laboratuvar analiz yöntemleri. KHGM, Şanlıurfa Araş. Enst. Müd. Yay. Genel Yayın No: 55, Teknik Yayın No:11, Şanliurfa, $75 \mathrm{~s}$.

Göney, S., 1976. Adana ovaları I. İstanbul Üniversitesi Yayın No: 2162, Coğrafya Enstitüsü Yayın No: 88, İstanbul, $179 \mathrm{~s}$.

Güler, C., 2009. Site characterization and monitoring of natural attenuation indicator parameters in a fuel contaminated coastal aquifer: Karaduvar (Mersin, SE Turkey): Environmental Earth Sciences, 59 (3), 631-643.

Güler, C., Alpaslan, M., Kurt, M.A. and Temel, A., 2010. Deciphering factors controlling trace element distribution in the soils of Karaduvar industrial-agricultural area (Mersin, SE Turkey). Environmental Earth Sciences, 60 (1), 203-218.

Güler, C., Kurt, M.A., Alpaslan, M., Akbulut, C., 2012. Assessment of the impact of anthropogenic activities on the groundwater hydrology and chemistry in Tarsus coastal plain (Mersin, SE Turkey) using fuzzy clustering, multivariate statistics and GIS techniques. Journal of Hydrology, 414-415, 435451.

Güler, C., Kurt, M. A. and Korkut, R. N., 2013. Assessment of groundwater vulnerability to nonpoint source pollution in a Mediterranean coastal zone (Mersin, Turkey) under conflicting land use practices. Ocean \& Coastal Management, 71, pp 141-152.

Gürbüz, K., 1997. Seyhan ve Ceyhan Delta'larının kronolojik evrimi ve bunların kıyı değişimine etkileri. Geosound, 30, 175190.

Gürbüz, K., 1999. An example for river course changes on a delta plain: Seyhan Delta (Çukurova plain, southern Turkey). In: Bozkurt, E. and Rowbotham, G. (eds) Aspects of Geology of Turkey II. Geological Journal, Special Issue, 34 (1-2), 211-222.

Gürbüz, K., 2003. Berdan Nehri'nin Kuvaterner'deki evrimi ve Tarsus'un tarihçesine jeolojik bir yaklaşım. İTÜ Avrasya Yerbilimleri Enstitüsü, Kuvaterner Çalıştayı IV, İstanbul, $79-83 \mathrm{~s}$.

Kosters, E.C., VanderZwaan, G.J. and Jorissen, F.J., 2000. Production, preservation and prediction of source-rock facies in deltaic settings. International Journal of Coal Geology, 43 (1-4), 13-26.

Köleli, N. and Halisdemir, B., 2005. Distribution of chromium, cadmium, nickel and lead in agricultural soils collected from Kazanli-Mersin, Turkey. International Journal of Environment and Pollution, 23 (4), 409-416.

Kurt, M.A., Güler, C., Alpaslan, M., Temel, A., 2008. Karaduvar (Mersin) tarım topraklarındaki bazı ağır metallerin kökeni ve dağılımının faktör analizi ve CBS yardımıyla belirlenmesi. 61. Türkiye Jeoloji Kurultayı, MTA, Ankara, Bildiri Özleri Kitabı, 17-18.

Kurt, M.A., Alpaslan, M., Temel, A. ve Güler, C., 2009a. Mersin ve Tarsus arasındaki tarım topraklarının bünyesi ve mineralojik özellikleri. 62. Türkiye Jeoloji Kurultayı, MTA, Ankara, Bildiri Özleri Kitabı, 124-125.

Kurt, M.A., Güler, C., Alpaslan, M. ve Akbulut, C., 2009b. MersinTarsus arasındaki bölge topraklarında ve yeraltı sularında nitrat ve nitrit düzeylerinin karşılaştırılması. 62. Türkiye Jeoloji Kurultayı, MTA, Ankara, Bildiri Özleri Kitabı, 524-525.

Kurt, M.A., Alpaslan, M., Güler, C. ve Temel, A., 2009c. DeliçayTarsus Çayı (Mersin) arasındaki tarım topraklarında ağır metal dağılımlarının CBS yardımıyla belirlenmesi. 62 Türkiye Jeoloji Kurultayı, MTA, Ankara, Bildiri Özleri Kitab1, 544-545.

Kurt, M. A., 2010. Deliçay-Tarsus Çayı (Mersin) Arasında Kalan Alandaki Toprak Profillerinin Mineralojisi, Toprak ve Su Kirliliğinin Araştırılması. Mersin Üniversitesi Fen Bilimleri Enstitüsü, Mersin, Doktora Tezi, $430 \mathrm{~s}$ (yayımlanmamış).

Lécuyer C., Bodergat A.M., Martineau F., Fourel F., Gürbüz K. and Nazik A. 2012. Water sources, mixing and evaporation in the 1 Akyatan lagoon, Turkey. Estuarine, Coastal and Shelf Science. 115, 200-209.

Öner, E., Uncu, L. ve Hocaoğlu, B., 2002. Türkiye'nin Doğu Akdeniz kıyılarında deniz seviyesi ve kıyı çizgisi değişimleri. Türkiye'nin Kıyı ve Deniz Alanları IV. Ulusal Konferansı. 5-8 Kasım 2002, İzmir Bildiriler Kitab1, 1237-1247.

Öner, E., Hocaoğlu, B., Uncu, L., 2005a: Tarsus Ovasının Jeomorfolojik Gelişimi ve Gözlükule Höyüğü. TURQUA-V, Türkiye Kuvaterner Sempozyumu. 2-5 Haziran 2005, İTÜ Avrasya Yerbilimleri Enstitüsü, İstanbul. Genişletilmiş Bildiri Özleri Kitabı, 82-89.

Öner, E., Hocaoğlu, B., Uncu, L., 2005b: Palaeogeographical Surveys around the Mound Gözlükule (Tarsus). In: Field Seasons 2001-2003 of the Tarsus-Gözlükule Interdisciplinary Research Project (ed. A. Özyar). Ege Yayınları, İstanbul, 69-82.

Pasternack, G.B. and Brown, K.J., 2006. Natural and anthropogenic geochemical signatures of floodplain and deltaic sedimentary strata, Sacramento-San Joaquin Delta, California, USA. Environmental Pollution, 141 (2), 295309. 
Prakongkep, N., Suddhiprakarn, A., Kheoruenromne, I., Smirk, M. and Gilkes, R.J., 2008. The geochemistry of Thai paddy soils. Geoderma, 144 (1-2), 310-324.

Ranasinghe, P.N., Fernando, G.W.A.R, Dissanayake, C.B., Rupasinghe, M.S. and Witter, D.L., 2009. Statistical evaluation of stream sediment geochemistry in interpreting the river catchment of high-grade metamorphic terrains. Journal of Geochemical Exploration, 103 (2-3), 97-114.

Ranasinghe, P.N., Fernando, G.W.A.R., Dissanayake, C.B. and Rupasinghe, M.S., 2008. Stream sediment geochemistry of the Upper Mahaweli River Basin of Sri LankaGeological and environmental significance. Journal of Geochemical Exploration, 99 (1-3), 1-28.

Singh, P., 2009. Major, trace and REE geochemistry of the Ganga River sediments: Influence of provenance and sedimentary processes. Chemical Geology, 266 (3-4), 242-255.

Şenol, M., 1989. Adana-Balcalı/Çatalan bölgesi Geç TersiyerKuvaterner istifinin Lito-pedolojik ve sedimantolojik incelemesi. Çukurova Üniversitesi Fen Bilimleri Enstitüsü, Adana, Doktora Tezi, 128 s (yayımlanmamış).

Şenol, M., Kapur, S. ve Şahin, Ş., 1993. Adana Havzası Kuvaterneri. İ.T.Ü. Maden Fak. Türkiye Kuvaterneri Workshop Bildiri Özleri, İstanbul, 24-27.

Şenol, M., Şahin, Ş. ve Duman T.Y., 1998. Adana-Mersin dolayının jeoloji etüd raporu. M.T.A., Ankara, $46 \mathrm{~s}$ (yayımlanmamış).
Tareq, S.M., Safiullah, S., Anawar, H.M., Rahman, M.M. and Ishizuka, T., 2003. Arsenic pollution in groundwater: a self-organizing complex geochemical process in the deltaic sedimentary environment, Bangladesh. The Science of the Total Environment, 313 (1-3), 213-226.

Topak, Y., 1997. Berdan Nehiri (Tarsus) Keşbükü-Kulaklı köyleri aras1 ağır metal analizleri ve mevsimsel hidrojeokimyasal değişimleri. Çukurova Üniversitesi Fen Bilimleri Enstitüsü, Adana, Yüksek Lisans Tezi, $180 \mathrm{~s}$ (yayımlanmamış).

Vaisanen, A. and Kiljunen, A., 2005. Ultrasound-assisted sequential extraction method for the evaluation of mobility of toxic elements in contaminated soils. Intern. J. Environ. Anal. Chem., 85 (14), 1037-1049.

Yaman, S., 1991. Mersin ofiyolitinin jeolojisi ve metallojenisi. Yetiş, C. (Ed.) Ahmet Acar Jeoloji Sempozyumu Bildiriler Kitab1, Adana, 225-267.

$\begin{array}{ll}\text { Makale Geliş Tarihi } & : \text { 31 Ekim } 2013 \\ \text { Kabul Tarihi } & : \text { 22 Kasim } 2013 \\ \text { Received } & : \text { 31 October } 2013 \\ \text { Accepted } & : \text { 22 November } 2013\end{array}$

